\section{Social support network, mental health and quality of life: a cross-sectional study in primary care}

\section{Rede de apoio social, saúde mental e qualidade de vida: um estudo transversal na atenção primária}

\section{Red de apoyo social, salud mental y calidad de vida: un estudio transversal en la atención primaria}

Flávia Batista Portugal 1 Mônica Rodrigues Campos 2 Celina Ragoni Correia ${ }^{3}$ Daniel Almeida Gonçalves 4 Dinarte Ballester 5 Luis Fernando Tófoli 6 Jair de Jesus Mari 4 Linda Gask 7 Christopher Dowrick 8

Peter Bower 7

Sandra Fortes 3

\begin{abstract}
The objective of this study was to identify the association between emotional distress and social support networks with quality of life in primary care patients. This was a cross-sectional study involving 1,466 patients in the cities of São Paulo and Rio de Janeiro, Brazil, in 2009/2010. The General Health Questionnaire, the Hospital Anxiety and Depression Scale and the brief version of the World Health Organization Quality of Life Instrument were used. The Social Support Network Index classified patients with the highest and lowest index as socially integrated or isolated. A bivariate analysis and four multiple linear regressions were conducted for each quality of life outcome. The means scores for the physical, psychological, social relations, and environment domains were, respectively, 64.7; 64.2; 68.5 and 49.1. In the multivariate analysis, the psychological domain was negatively associated with isolation, whereas the social relations and environment domains were positively associated with integration. Integration and isolation proved to be important factors for those in emotional distress as they minimize or maximize negative effects on quality of life.
\end{abstract}

Primary Health Care; Mental Health; Quality of Life; Social Support

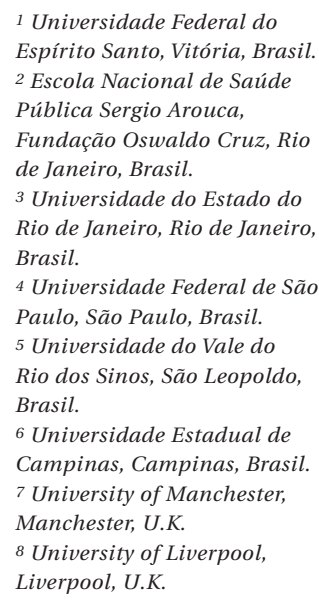

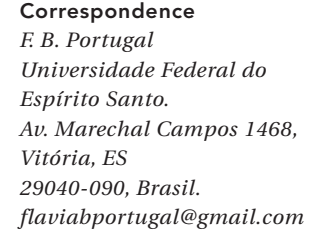




\section{Background}

Nowadays, it is accepted that disease is a multicausal process in which several factors are associated with the evolution of illness. Evidence shows that good personal relationships and integration within a community have a positive impact on the health of individuals, so the social support network is an important component of health promotion 1 .

The social support network is understood as any support coming from people who know each other and that results in positive emotional effects, acting as an important positive psychosocial factor and generating greater satisfaction with life 2 . A network can be understood as the available social resources which are expressed by relationships of reciprocity and affection between those involved in it 3 .

Kawachi \& Berkman 4 indicate that social ties have multiple levels, all of which may be associated with benefits to health. They divide social relations into intimate relations (such as marriage); outward to social networks (such as closeness with relatives and friends); and "weak" ties, (which consist of participation in community activities, volunteer work and participation in religious organizations). The latter, although not intensely promoting person-to-person interactions, provides a sense of belonging and social identity, which is relevant to the promotion of psychological well being 4 .

It is important to mention the positive influence of the social support network in cases of mental disorder. The feeling of being loved and cared for is related to lower levels of anxiety, depression and somatization, as well as to better adaptation to stressful situations 5. The study conducted in Family Health Units in the city of Petrópolis, Rio de Janeiro State, Brazil, is an example of this. The study showed that going regularly to church, participating in sports/artistic activities and having at least four members in one's family on whom one can count is associated with a lower presence of common mental disorder 6 .

Quality of life is a broad concept, with many definitions. Due to the need for a transcultural concept, the World Health Organization (WHO) gathered experts from around the world through the Quality of Life Group (WHOQOL Group) and defined quality of life as an individual's perception of their position in life in the context of the culture and the value systems in which they live and in relation to their goals, expectations, standards and concerns 7 . From quality of life measures of individuals we can ascertain a wider view of how different types of disorders and their treatment affect patients' lives. In addition we can identify variables, such as social ones, that may help the development of new preventive and therapeutic strategies 8 . In the field of health services evaluation, quality of life emerges as an important instrument for assessing health services since it assures that treatment and its assessment is focused on the patient and not only on the disease ${ }^{9}$.

According to the WHO's concept for quality of life, various psychosocial factors influence a person's health. Therefore, it is important to know what these factors are and how they impact on people. Among them we may include emotional distress and the social support network, an association which has already been addressed in some studies 9,10,11,12,13. However, questions remain as to how mental disorders behave in relation to social support and quality of life. While some studies indicate that the social support network has a positive association with quality of life of patients with mental disorders 13,14 , one study reports that the effect of the social support network does not minimize the effect of emotional distress on quality of life 10 .

In our study we proposed the following research questions:

What are the characteristics (socioeconomic/ demographic, mental status and being isolated/ integrated) associated with the four domains of quality of life?

How do the socioeconomic/demographic, mental status and the presence of being isolated/ integrated (independent variables) interact in relation to quality of life (dependent variable) of primary care patients?

This article focuses on the associations between emotional distress and the social support network and quality of life of primary care patients from Rio de Janeiro and São Paulo, Brazil, in 2009 and 2010.

\section{Methods}

\section{Type of study}

This is a cross-sectional study conducted in the municipalities of Rio de Janeiro and São Paulo in the years of 2009 and 2010. The original study aim was to assess the impact of mental health training courses on primary mental health activities in four centers in Brazil that participated in the project entitled Evaluation of a Training Model in Primary Care Mental Health: Matrix Support as a Practice of Comprehensive Collaborative Care. The training courses aimed to integrate family health and mental health teams through the implementation of the Brazilian model of col- 
laborative care, the matrix support activities and therapeutic interventions on mental health 15,16.

\section{Population studied}

Family Health Teams (FHT) appointed by the municipal authorities participated in the training courses. The city of Rio de Janeiro had the largest number of classes. Patients in the original study consisted of individuals seen by teams (a doctor and nurse) with an average of 30 patients per team and the study was conceived as two cross sectional surveys in a quasi-experimental pre-post design. The first cross sectional survey was carried out from September to November 2009 and the second survey from June to August 2010. No patient who participated in the first survey was allowed to participate in the second. For this analysis the entire sample was gathered and analyzed together. Patients were between 18 and 65 years of age, and did not include pregnant women and patients with cognitive deficit. In all, 1,466 primary care patients participated in this study, from Rio de Janeiro ( $\mathrm{n}=909$ ) and São Paulo $(\mathrm{n}=557)$.

\section{Instruments}

\section{- Socioeconomic and demographic questionnaire}

The socioeconomic and demographic variables were obtained by means of a closed questionnaire used in previous research6. The following variables were analyzed: gender (male/female), age group (up to 40 / above 40 years of age), school education (up to 4 th grade/higher than 4 th grade in primary school) and per capita family income for month (up to the minimum wage $(\leq \$ 232.50$ at that moment) / higher than the minimum wage (> \$232.50).

\section{- World Health Organization Quality of Life Instrument, brief version}

The World Health Organization Quality of Life Instrument, brief version (WHOQOL-BREF), contains 26 questions regarding the two previous weeks. The instrument measures four quality of life domains: physical, psychological, social relationships and environment. Moreover, the instrument contains two questions about the individual's assessment of quality of life and one about satisfaction with their own health. The WHOQOL-BREF has satisfactory psychometric properties and is widely used in Brazilian research 17 .

\section{- General Health Questionnaire}

The General Health Questionnaire (GHQ-12) was developed by Goldberg \& Blackwell 18 and validated in Brazil against the Clinical Interview Schedule 19. It is a tracking instrument for common mental disorders, which are disorders commonly occurring in the community and their presence indicates an alteration in regard to normal functioning 20 . The GHQ-12 consists of 12 questions, all relating to the previous two weeks 21 .

As can be seen in the literature 22 , two cut-off points can be used for tracking common mental disorders. This study considered those with 3 or 4 points as positive for common mental disorders (CMD3) and those with 5 or more as positive for severe common mental disorders (CMD5).

\section{- Hospital Anxiety and Depression Scale}

The Hospital Anxiety and Depression Scale (HAD) was developed for detecting mild degrees of affective disorder (anxiety and depression), and it has been adapted to the Brazilian context 23 . It contains 14 questions relating to the previous two weeks, subdivided into two subscales, one for anxiety and one for depression. For the analysis, the cut-off point of $8 / 9$ was used for probable cases of depression (DEP+) and anxiety (ANX+) 23 .

\section{- Social Network Index}

The Social Network Index (SNI) was obtained through a questionnaire developed by Chor et al. 24, which was adapted from Berkman \& Syme's instrument 25 . This index consists of a measurement of four kinds of social relationships: marital status, number of relatives or close friends, participation in sports/arts/group activities (e.g.: community organizations) and regularity in church attendance ${ }^{25}$. The SNI was calculated based on the proposal made by Loucks et al. ${ }^{26}$, as carried out in a previous study 27 , and its sum is calculated as follows: having a partner (no = 0 , yes $=1$ ); number of close relatives and friends (from 0-2 relatives and from 0-2 close friends = 0 , any other combination $=1)$, participation in church and religious activities (2 times/month or more $=1$, other $=0$ ), participation in sports $/$ arts $/$ group activities (no $=0$, yes $=1$ ).

We chose to investigate the social support construct by means of two extreme and nonsupplementary categories (the middle category was excluded) from the SNI, which correspond to approximately $30 \%$ of the cases at the upper and lower limits of the index: being integrated (total = 3 or 4 ) and being isolated (total $=0$ or 1 ). 


\section{Statistical analysis}

A bivariate analysis was conducted by verified means difference of quality of life score on ttest ( $5 \% \mathrm{p}$-value of significance level) between dichotomous exposure variables categories (socioeconomic/demographic, mental status and being isolated/ integrated), for each one of four domains quality of life outcomes. The independent variables that were statistically significant at the bivariate analysis (at the significance level of $10 \%$ ) were selected for the multiple linear regression models, which had the four quality of life domains as outputs (dependent variables). Considering the probable collinearity of the mental status variables, it four regression model sets were made, as follows:

1. Model 1: for all positive patients for CMD5, probable cases of anxiety and probable cases of depression;

2. Model 2: exclusively positive cases of CMD5;

3. Model 3: exclusively positive cases of probable cases of anxiety and;

4. Model 4: exclusively positive cases of probable cases of depression.

The multiple linear regressions were conducted by backward stepwise selection, considering each quality of life domain as an output. In multivariate analysis, the coefficient of determination $\left(\mathrm{R}^{2}\right)$, the coefficients of the multiple linear regressions of each independent variable, and their significance levels were presented. Diagnostic analysis of the residues of each regression model was performed, and they are satisfactory in terms of the coefficient of determination achieved. The SPSS software, version 17 (SPSS Inc., Chicago, U.S.A.), was used.

\section{Ethical issues}

The intervention study was approved by the Ethics Research Committees of the Municipal Secretariats of the cities of Rio de Janeiro (no 34/09) and São Paulo (no 66/09). Additionally, the project that reported this article was submitted to and approved by the Ethics Committee of the Sergio Arouca National School of Public Health, Oswaldo Cruz Foundation (ENSP/Fiocruz) (n ${ }^{\circ}$ $272,157 / 2013$ ). All the patients participating in the research provided written informed consent. They were informed about the objectives of the research and their anonymity was assured.

\section{Results}

Of the 1,466 individuals who participated from São Paulo and Rio de Janeiro, the largest profile groups were: women $(76.5 \%)$, aged 40 or more (62.6\%), with school education beyond than the fourth grade of primary school (66.7\%) and per capita family income lower than the minimum wage (\$202.17) (74.4\%). Results showed that 37\% were probable cases of anxiety, $32 \%$ met criteria for CMD5, 25.1\% were probable cases of depression and $20.5 \%$ met criteria for CMD3 15 . In terms of social support networks, integration was found in $30.5 \%$ of cases and isolation in $33.6 \%$ (Table 1 ).

Regarding quality of life, the average scores for the physical, psychological, social relationships and environment domains were respectively, 64.7, 64.2, 68.5 and 49.1. Through the bivariate analysis the lowest quality of life scores were found in women, for those with per capita family income lower than the minimum wage, for CMD5 and for anxiety and depression in all domains ( $p$-value $<5 \%$ ). Those above 40 years of age presented lower scores for physical and social relation domains ( $p$-value $<5 \%$ ). Those with school education below the fourth grade of primary school presented lower scores for physical, psychological and environment domains ( $p$ value $<5 \%$ ). Among the mental status variables, only the variable CMD3 did not present a p-value $<10 \%$, and was therefore excluded from the multiple linear regression model (Table 1).

Regarding the variables for social support network and quality of life, having close relatives or friends and participating in sports/arts/group activities was associated with higher quality of life scores on all domains ( $p$-value $<5 \%$ ). However, being married or having a partner was positively associated only with the social relationships domain ( $p$-value $<5 \%$ ). When the SNI was used, higher scores were found for integrated patients and lower scores for isolated ones, with statistical differences in all of the domains (Table 1).

Through the multivariate analysis (Table 2) four models were performed, considering the mental status variables: the first included all variables selected in this study (sex, age group, school education, per capita family income, and being isolated/ integrated) and CMD5, probable cases of anxiety and probable cases of depression, where we expected collinearity to occur The other three models were made for each mental status variable (Model 2: CMD5; Model 3: probable cases of anxiety; and Model 4: probable cases of depression).

Model 1 was able to account for $32 \%$ of the variance in physical quality of life, $43 \%$ of the variance in psychological quality of life, $15 \%$ of the variance in the social relationships domain and $20 \%$ of the variance in the environment domain. In analyzing the other models, there is a reduction in the $\mathrm{R}^{2}$ in all domains. For the physical 


\section{Table 1}

Mean scores of quality of life based on socioeconomic characteristics, mental status and social support network. Rio de Janeiro and São Paulo, Brazil, 2009/2010.

\begin{tabular}{|c|c|c|c|c|c|}
\hline \multirow[t]{2}{*}{ Characteristics } & \multirow[t]{2}{*}{$\%$} & \multicolumn{4}{|c|}{ Quality of life } \\
\hline & & Physical (64.7) & Psychological (64.2) & Social relations (68.5) & Environment (49.1) \\
\hline \multicolumn{6}{|l|}{ Socioeconomic characteristics } \\
\hline \multicolumn{6}{|l|}{ Sex } \\
\hline Female & 76.5 & 63.7 * & 62.9 * & 67.9 * & 48.2 * \\
\hline Male & 23.5 & 67.9 * & 68.8 * & 70.3 * & 52.2 * \\
\hline \multicolumn{6}{|l|}{ Age group (years) } \\
\hline Up to 40 & 37.4 & 68.1 * & 64.9 & 70.2 * & 48.8 \\
\hline Above 40 & 62.6 & 62.7 * & 63.9 & 67.5 * & 49.3 \\
\hline \multicolumn{6}{|l|}{ School education } \\
\hline Up to 4 th grade & 33.3 & 61.6 * & 61.5 * & 68.3 & 48.1 * \\
\hline Higher than $4^{\text {th }}$ grade ** & 66.7 & 66.3 * & 65.7 * & 68.6 & 49.6 * \\
\hline \multicolumn{6}{|l|}{ Per capita family income } \\
\hline Up to minimum wage & 74.4 & 63.9 * & 63.1 * & 67.7 * & 47.9 * \\
\hline Higher than minimum wage & 25.6 & 67.7 * & 68.4 * & 71.4 * & 52.8 * \\
\hline \multicolumn{6}{|l|}{ Mental status } \\
\hline \multicolumn{6}{|l|}{ CMD3 } \\
\hline No & 79.5 & 65.0 & 64.2 & 68.6 & 49.3 \\
\hline Yes & 20.5 & 63.6 & 64.7 & 68.1 & 48.4 \\
\hline \multicolumn{6}{|l|}{ CMD5 } \\
\hline No & 68.0 & 70.4 * & 70.0 * & 72.5 * & 52.3 * \\
\hline Yes & 32.0 & 52.6 * & $52.1 *$ & 60.0 * & 42.4 * \\
\hline \multicolumn{6}{|l|}{ Anxiety } \\
\hline No & 63.0 & 70.3 * & 70.2 * & 72.5 * & 52.5 * \\
\hline Yes & 37.0 & 55.2 * & 54.2 * & 61.7 * & 43.4 * \\
\hline \multicolumn{6}{|l|}{ Depression } \\
\hline No & 74.9 & 68.7 * & 69.1 * & 71.2 * & 51.8 * \\
\hline Yes & 25.1 & 52.8 * & 49.8 * & 60.3 * & 41.0 * \\
\hline \multicolumn{6}{|l|}{ Social support network } \\
\hline \multicolumn{6}{|l|}{ Marital status } \\
\hline Marriage/Stable union & 62.5 & 64.9 & 64.7 & 69.5 * & 49.5 \\
\hline Others & 37.5 & 64.4 & 63.5 & 66.8 * & 48.4 \\
\hline \multicolumn{6}{|l|}{ Relatives or close friends } \\
\hline No & 57.7 & 63.2 * & 62.1 * & 65.8 * & 47.5 * \\
\hline Yes & 42.3 & 66.8 * & 67.3 * & 72.1 * & 51.3 * \\
\hline \multicolumn{6}{|l|}{ Participation in group activities } \\
\hline No & 70.9 & 63.3 * & 62.7 * & 67.8 * & 48.0 * \\
\hline Yes & 29.1 & 68.1 * & 68.2 * & 70.1 * & 51.8 * \\
\hline \multicolumn{6}{|c|}{$\begin{array}{l}\text { Participation in church and religious } \\
\text { activities (at least twice a month) }\end{array}$} \\
\hline No & 38.4 & 65.4 & 64.1 & 67.9 & 49.5 \\
\hline Yes & 61.6 & 64.2 & 64.4 & 68.9 & 49.0 \\
\hline \multicolumn{6}{|l|}{ Being integrated } \\
\hline No & 68.9 & 63.5 * & 62.8 * & 66.8 * & 48.0 * \\
\hline Yes & 30.5 & 67.5 * & 67.8 * & 72.4 * & 52.0 * \\
\hline \multicolumn{6}{|l|}{ Being isolated } \\
\hline No & 66.4 & 65.4 * & 65.8 * & 69.7 * & 50.1 * \\
\hline Yes & 33.6 & 63.3 * & 61.2 * & 66.3 * & 47.5 * \\
\hline
\end{tabular}

* Data with an asterisk are the results in which $p$-value $<5 \%$ in t-test for means difference;

** Primary school. 
Table 2

Backward linear regression models for the quality of life outputs on the different domains. Rio de Janeiro and São Paulo, Brazil, $2009 / 2010$.

\begin{tabular}{|c|c|c|c|c|c|c|c|c|}
\hline \multirow[t]{2}{*}{ Independent variables } & \multicolumn{2}{|c|}{ Physical } & \multicolumn{2}{|c|}{ Psychological } & \multicolumn{2}{|c|}{ Social relationships } & \multicolumn{2}{|c|}{ Environment } \\
\hline & $\beta$ * & $p^{* \star}$ & $\beta$ * & $p * \star$ & $\beta$ * & $p$ ** & $\beta$ * & $p^{* *}$ \\
\hline \multicolumn{9}{|c|}{ Model 1: mental status (CMD5, anxiety or depression) } \\
\hline $\mathrm{R}^{2}$ & \multicolumn{2}{|c|}{0.32} & \multicolumn{2}{|c|}{0.43} & \multicolumn{2}{|c|}{0.15} & \multicolumn{2}{|c|}{0.20} \\
\hline Constant & 76.1 & 0.000 & 66.7 & 0.000 & 80.9 & 0.000 & 52.3 & 0.000 \\
\hline Age group & -4.5 & 0.000 & - & - & -3.5 & 0.000 & - & - \\
\hline School education & 2.3 & 0.007 & 3.2 & 0.000 & - & - & - & - \\
\hline Per capita family income & - & - & 2.0 & 0.007 & 2.1 & 0.047 & 3.3 & 0.000 \\
\hline CMD5 & -11.8 & 0.000 & -9.6 & 0.000 & -7.5 & 0.000 & -5.0 & 0.000 \\
\hline Anxiety & -7.0 & 0.000 & -7.0 & 0.000 & -5.4 & 0.000 & -4.5 & 0.000 \\
\hline Depression & -6.7 & 0.000 & -11.0 & 0.000 & -3.9 & 0.001 & -5.7 & 0.000 \\
\hline Being integrated & - & - & - & - & 3.8 & 0.000 & 1.9 & 0.006 \\
\hline Being isolated & - & - & -2.3 & 0.001 & - & - & - & - \\
\hline \multicolumn{9}{|c|}{ Model 2: mental status (only by CMD5) } \\
\hline $\mathrm{R}^{2}$ & \multicolumn{2}{|c|}{0.26} & \multicolumn{2}{|c|}{0.30} & \multicolumn{2}{|c|}{0.12} & \multicolumn{2}{|c|}{0.14} \\
\hline Constant & 71.2 & 0.000 & 61.8 & 0.000 & 75.4 & 0.000 & 50.5 & 0.000 \\
\hline Age group & - & - & 2.0 & 0.024 & - & - & - & - \\
\hline School education & -4.8 & 0.000 & - & - & -3.1 & 0.001 & - & - \\
\hline Per capita family income & 2.5 & 0.006 & 3.5 & 0.000 & - & - & - & - \\
\hline CMD5 & - & - & 2.1 & 0.016 & 2.1 & 0.041 & 3.5 & 0.000 \\
\hline Anxiety & -17.4 & 0.000 & -17.1 & 0.000 & -11.6 & 0.000 & -9.4 & 0.000 \\
\hline Depression & 2.0 & 0.023 & - & - & 4.2 & 0.000 & 2.5 & 0.001 \\
\hline Being integrated & - & - & -2.6 & 0.001 & - & - & - & - \\
\hline \multicolumn{9}{|c|}{ Model 3: mental status (only by anxiety) } \\
\hline $\mathrm{R}^{2}$ & \multicolumn{2}{|c|}{0.12} & \multicolumn{2}{|c|}{0.27} & \multicolumn{2}{|c|}{0.11} & \multicolumn{2}{|c|}{0.15} \\
\hline Constant & 69.4 & 0.000 & 60.5 & 0.000 & 75.5 & 0.000 & 46.5 & 0.000 \\
\hline Age group & 2.6 & 0.010 & 2.9 & 0.001 & - & - & 1.7 & 0.032 \\
\hline School education & -5.1 & 0.000 & - & - & -3.2 & 0.001 & - & - \\
\hline Per capita family income & 2.6 & 0.007 & 3.7 & 0.000 & - & - & - & - \\
\hline CMD5 & 1.9 & - & 2.7 & 0.002 & 2.8 & 0.009 & 3.5 & 0.000 \\
\hline Anxiety & -14.3 & 0.000 & -15.2 & 0.000 & -10.2 & 0.000 & -8.7 & 0.000 \\
\hline Depression & 2.4 & - & - & - & 4.5 & 0.000 & 2.6 & 0.000 \\
\hline Being integrated & - & - & -3.3 & 0.000 & - & - & - & - \\
\hline \multicolumn{9}{|c|}{ Model 4: mental status (only by depression) } \\
\hline $\mathrm{R}^{2}$ & \multicolumn{2}{|c|}{0.19} & \multicolumn{2}{|c|}{0.31} & & & & \\
\hline Constant & 66.8 & 0.000 & 60.2 & 0.000 & 73.5 & 0.000 & 46.1 & 0.000 \\
\hline Age group & 2.4 & 0,020 & 2.5 & 0.005 & - & - & - & - \\
\hline School education & -4.4 & 0,000 & - & - & -2.8 & 0.003 & - & - \\
\hline Per capita family income & 2.8 & 0,003 & 3.6 & 0.000 & - & - & - & - \\
\hline CMD5 & 2.1 & 0,040 & 2.7 & 0.001 & 2.9 & 0.007 & 3.6 & 0.000 \\
\hline Anxiety & -14.9 & 0,000 & -18.5 & 0.000 & -10.0 & 0.000 & -10.0 & 0.000 \\
\hline Depression & 2.4 & 0,010 & - & - & 4.6 & 0.000 & 2.5 & 0.001 \\
\hline Being integrated & - & - & -3.1 & 0.000 & - & - & - & - \\
\hline
\end{tabular}

* $\beta$ is the coefficient of each independent variable per regression on each model according to the quality of life domain;

** $p$-value of $\beta$ 's coefficient in Wald test.

Note: Variables added in the regression: Sex ( $0=$ Female/1 $=$ Male), Age group ( $0=$ up to 40 years $/ 1=$ Above 40 years), School education

$(0=$ up to 4 th grade $/ 1=$ higher than 4 th grade in primary school), Per capita family income $(0=$ up to the minimum wage $/ 1=$ higher than to the minimum wage), $\operatorname{CMD} 5(0=\mathrm{No} / 1=$ Yes $)$, Anxiety $(0=\mathrm{No} / 1=\mathrm{Yes})$, Depression $(0=\mathrm{No} / 1=$ Yes $)$, Being integrated $(0=\mathrm{No} / 1=\mathrm{Yes})$, and Being isolated $(0=\mathrm{No} / 1=\mathrm{Yes})$. 
domain, for example, Model 3 only accounted for $12 \%$ of the variance. For the social relationships domain, Model 4 was able to account for only $9 \%$ of the variance (Table 2).

Concerning the simultaneous effect of the social support network, controlling for socioeconomic/demographic and emotional distress characteristics (multiple linear regression - Models 2, 3 and 4), it is important to highlight the negative effect of isolation on the psychological domain and the positive effect of integration on the physical, social relationships and environment domains. For Models 2, 3 and 4, it is also important to note that integration resulted in a higher association in social network and environmental domains of quality of life and isolation for the psychological domain compared to Model 1 (CMD5, anxiety and depression) (Table 2).

\section{Discussion}

The average quality of life scores for the physical, psychological, social relationships and environment domains were, respectively, 64.7, 64.2, 68.5 and 49.1. Higher quality of life scores were found for integrated patients and lower scores for isolated ones, with statistical differences in all quality of life domains.

Model 1 had the highest $\mathrm{R}^{2}$ for all domains when compared to other models considered in the multiple linear regression. Instruction and per capita family income had positive influence on quality of life. In the presence of more severe emotional distress, whether CMD5, anxiety or depression, there was a substantial drop in quality of life, which was controlled by the socioeconomic variables (multiple linear regression). Regarding the social support network, the psychological domain presented a negative association with being isolated and physical, social relationships and environment domains of quality of life were positively associated with being integrated (as demonstrated in Models 2, 3 and 4 of the regression).

This study demonstrated that the presence of any type of emotional distress was associated with lower quality of life scores, as previously reported in the literature 28,29,30. A study conducted in England found lower scores for those suffering from common or severe mental disorder compared to those considered healthy; in turn, those suffering from severe mental disorder scored still lower than those from the other two analysis groups (healthy and suffering from common mental disorder) ${ }^{31}$. A study from the city of Porto Alegre in Southern Brazil, carried out in the entire population, found lower quality of life scores among those that reported depression and anxiety in all domains measured by WHOQOL-BREF (p-value < 0.001) 32. In another study in the same city, patients with Parkinson's disease that participated in a support group presented better quality of life ( $p=0,002)$, less depression ( $p=$ $0,026)$, less anxiety $(\mathrm{p}<0,001)$ and social phobia ( $p=0,01$ ) than those that did not come to the group 33. A further study, from London (England), found higher quality of life scores in the presence of a social support network in the case of psychotic patients 14 .

From the multiple linear regression, no social network variable was found to remain in Model 1 for the physical domain. On the other hand, when we stratified the models by mental status variable (Models 2, 3, and 4) being integrated appeared in the physical domain for all types of psychological distress (CMD5, probable cases of anxiety and depression). A study conducted in Malaysia found that depression and social support were the only factors associated with the physical domain of 12-item Short Form (SF-12) after logistic regression ${ }^{34}$. In another study with elderly subjects in Malaysia, using multiple linear regression, social support was significantly associated with better quality of life in all four domains of the WHOQOL-BREF 35 .

CMD5 is highlighted as the variable that most influenced variability in Model 1. Analyzing Models 2, 3 and 4, CMD5 was the mental health variable that presented the highest $\beta$. CMD5 is characterized by non-specified and self-perceived suffering, which may present at the health service in the form of unexplainable medical complaints 6,36. According to Tófoli et al. 37, unexplainable medical complaints expressed as diffuse physical symptoms, such as insomnia and fatigue, are generally associated with anxiety and depression syndromes, are quite common in Latin populations, and considered as a cultural representation of emotional distress 34 . Therefore, the higher negative association with CMD5 found for the physical domain may be related to this type of emotional distress disclosure in the Brazilian population, as detected in a previous study 30 .

It is important to note that "being isolated" was maintained in the four models only for the psychological domain. This result confirms the findings of a study conducted in the UK with elderly patients in which being isolated was associated with the mental component of SF-12 38 . Being isolated can be considered as the absence of contact with other people 38,39 . However, a broader approach must be considered where being isolated includes both the number of people and the quality of these relationships 39 . 
Finally, the social relation domain is directly related to integration variable as it addresses issues related to personal relationships and perceived social support. The same happens with the environment domain as it also includes leisure activities, as mentioned previously. Both domains encompass social activities that promote the development of social relationships 17,40 , thus these two components of quality of life improve when social integration is achieved.

\section{Strengths and weaknesses of the study}

The first strength of this study is that it is a multivariate analysis in primary care from two large Brazilian cities providing information on quality of life for these patients. A second strength is the use of a transcultural instrument for measuring quality of life, the WHOQOL-BREF, and the fact that the other instruments used (GHQ-12 and $\mathrm{HAD}$ ) have also been validated and adapted to the Brazilian context, and are widely used in the literature 19,23, which makes it possible to compare the data from Brazil with results from international studies.

However, certain weaknesses should be mentioned. Firstly, this study is limited to primary care patients. Therefore, its results may not be extrapolated to the general population. Additionally, given the cross-sectional nature of this study, exposure and outcome are measured simultaneously, which include the possibility of reverse causality. Therefore, in this article we are limited to discuss the association between the factors studied. The causal risk type associations cannot be assessed.

The patients were not recruited from the community and also those who refused to participate were not included in the analysis; consequently it was not possible to estimate the true prevalence and the results cannot be rigorously extrapolated for the population of each city. However, this sample should be comparable to the primary care practice routine of other urban areas in Brazil. The samples were from two cross sectional surveys conducted at different times but were considered homogeneous enough for pooled analysis.

One further weakness is the use of the instruments for tracking mental disorders (GHQ-12 and HAD), which only identify the probable cases of emotional distress and not their diagnostic status. Therefore, it is possible that false-positives are detected, thus increasing the proportion of emotional distress cases.

The SNI is widely used internationally. However, we still have to take into account the issue of the transcultural issues applied to the Brazil- ian setting. Each culture has its own peculiarities. What is considered to be an integrated or isolated person in the Brazilian context might not be the same in the context of other countries.

\section{Implications for clinical practice and for research}

This study confirmed that higher income and higher educational levels were positively associated with quality of life as demonstrated in the literature ${ }^{41}$. Macro level interventions are necessary, through government policies aimed at reducing social inequalities, in order to generate better conditions for health. Nevertheless, direct action at the health service level may generate significant improvements in the health of the population. In this context, if quality of life is measured it may become an indicator for the assessment of health status at primary care in a broader spectrum. quality of life allows for the identification and prioritization of problems since its measurement offers a wide variety of information about conditions of life and health status of an individual. Moreover, the results obtained from measuring quality of life allow health professionals and patients to share decisions in order to identify priorities for treatment and to establish realistic goals 9 .

Even in the presence of mental disorders of higher intensity (CMD5, probable cases of anxiety and depression), being integrated has a positive association for the quality of life in the physical, social network and environment domains. Thus, it is possible to suggest that in some cases of emotional distress, such as anxiety, psychosocial actions may generate more significant positive effects on the lives of patients 27 . The Brazilian Ministry of Health encourages the implementation of groups in primary care, especially for those in emotional distress, and determines that care in mental health should include simple interdisciplinary interventions and actions conducted in partnership with other sectors, encouraging patient participation in community circles such as church, community organizations and others activities in their territory 42 .

The development of interventions to increase social network support is an important role for primary care professionals, since they can minimize the negative effects of mental illness or be a protective effect for development of mental disorders. Specifically for the physical domain, integration appeared to be a protective factor in the regression models for CMD5, which are probable cases of anxiety and depression. This may suggest the need for groups to promote physical activities in primary care, since it can help prevent 
and limit the impact of physical illness as well as contribute to the expansion and strengthening of the social network support.

Very often patients in emotional distress are not identified as suffering from a mental disorder 43 and those who are identified may not receive adequate treatment for their condition 44 This issue points to the need for training primary care professionals in how to properly deal with emotional distress. Such training should address diagnosis, treatment and psychosocial interventions 6 .

Finally, due to the cross-sectional characteristic of the present study, there is the possibility of reverse causality, denoting the need for longitudinal studies, through which it will be pos- sible to better identify the directionality of the influence of social support (being isolated or integrated) together with emotional distress and quality of life, over time. The variables chosen partially explained the outcome, which calls for the development of a broader theoretical model including other variables such as, for instance, access to care, the characteristics of health services and user satisfaction. Another important issue to be considered is investigating the social support network, which has different meanings for different cultures 45 and therefore demands the development of instruments and indicators that take into account the particularities of the Brazilian context.

\section{Contributors}

F. B. Portugal contributed towards the database analysis and the writing of the article. M. R. Campos and S. Fortes contributed towards defining the study scope, database analysis and writing the article. C. R. Correia contributed towards the database analysis. L. F. Tófoli, D. Ballester, D. A. Gonçalves, and J. J. Mari contributed towards defining the study scope, and writing the article. L. Gask, C. Dowrick, and P. Bower collaborated with the final revision of the article.

\section{Acknowledgments}

To the Brazilian National Research Council (CNPq) for their financial support.

\section{References}

1. Berkman LF. The role of social relations in health promotion. Psychosom Med 1995; 57:245-54.

2. Valla VV. Educação popular, saúde comunitária e apoio social numa conjuntura de globalização. Cad Saúde Pública 1999; 15 Suppl 2:7-14.

3. Gottlieb BH, Bergen AE. Social support concepts and measures. J Psychosom Res 2010; 69:511-20.

4. Kawachi I, Berkman LF. Social ties and mental health. J Urban Health 2001; 78:458-67.

5. Costa AG, Ludermir AB. Transtornos mentais comuns e apoio social: estudo em comunidade rural da Zona da Mata de Pernambuco, Brasil. Cad Saúde Pública 2005; 21:73-9.

6. Fortes S, Lopes CS, Villano LAB, Campos MR, Gonçalves DA, Mari JJ. Common mental disorders in Petrópolis-RJ: a challenge to integrate mental health into primary care strategies. Rev Bras Psiquiatr 2011; 33:150-6.

7. The WHOQOL Group. The World Health Organization quality of life assessment (WHOQOL): position paper from the World Health Organization. Soc Sci Med 1995; 10:1403-9.

8. Lima AFBS. Avaliação da qualidade de vida e fatores preditores de remissão de sintomas em pessoas com depressão maior acompanhadas através de um estudo longitudinal em um serviço de cuidados primários. Porto Alegre: Universidade Federal do Rio Grande do Sul; 2008.

9. Higginson IJ, Carr AJ. Measuring quality of life: using quality of life measures in the clinical setting. BMJ 2001; 322:1297-300.

10. Panayiotou G, Karekla M. Perceived social support helps, but does not buffer the negative impact of anxiety disorders on quality of life and perceived stress. Soc Psychiatry Psychiatr Epidemiol 2013; 48:283-94. 
11. Rüesch P, Graf J, Meyer PC, Rössler W, Hell D. Occupation, social support and quality of life in persons with schizophrenic or affective disorders. Soc Psychiatry Psychiatr Epidemiol 2004; 39:686-94.

12. Strine TW, Chapman DP, Balluz L, Mokdad AH. Health-related quality of life and health behaviors by social and emotional support: their relevance to psychiatry and medicine. Soc Psychiatry Psychiatr Epidemiol 2007; 43:151-9.

13. Wong WK, Chou KL, Chow NW. Correlates of quality of life in new migrants to Hong Kong from mainland China. Soc Indic Res 2012; 107:373-91.

14. Becker T, Leese M, Clarkson P, Taylor RE, Turner D, Kleckham J, et al. Links between social network and quality of life: an epidemiologically representative study of psychotic patients in south London. Soc Psychiatry Psychiatr Epidemiol 1998; 33:229-304.

15. Fortes S. Avaliação de um modelo de capacitação em saúde mental na atenção básica: cuidados integrais na prática do matriciamento. Relatório de pesquisa: 2009. http://lipapsuerj.blogspot.com. br/2012/10/formacao.html.

16. Gonçalves DA, Mari JJ, Bower P, Gask L, Dowrick C, Tófoli LF, et al. Brazilian multicentre study of common mental disorders in primary care: rates and related social and demographic factors. Cad Saúde Pública 2014; 30:623-32.

17. Fleck MP, Louzada S, Xavier M, Chachamovich E, Vieira G, Santos L, et al. Aplicação da versão em português do instrumento abreviado de avaliação da qualidade de vida "WHOQOL-bref". Rev Saúde Pública 2000; 34:178-83.

18. Goldberg DP, Blackwell B. The detection of psychiatric illness by questionnaire. London: Oxford University Press; 1972.

19. Mari JJ, Williams P. A comparison of the validity of two psychiatric screening questionnaires (GHQ12 and SRQ-20) in Brazil, using Relative Operating Characteristic (ROC) analysis. Psychol Med 1985; 15:651-9.

20. Goldberg D, Huxley P. Common mental disorders: a bio-social model. London: Tavistock/Routledge; 1992.

21. Goldberg DP, Blackwell B. Psychiatric illness in general practice. A detailed study using a new method of case identification. BMJ 1970; 1:439-43.

22. Fortes S. Transtornos mentais na atenção primária: suas formas de apresentação, perfil nosológico e fatores associados em unidades do Programa de Saúde da Família do município de Petrópolis/Rio de Janeiro/Brasil. Rio de Janeiro: Universidade do Estado do Rio de Janeiro; 2004.

23. Botega NJ, Bio MR, Zomignani MA, Garcia Jr. C, Pereira WAB. Transtornos do humor em enfermaria de clínica médica e validação de escala de medida (HAD) de ansiedade e depressão. Rev Saúde Pública 1995; 29:359-63.

24. Chor D, Griep RH, Lopes CS, Faerstein E. Medidas de rede e apoio social no Estudo Pró-Saúde: pré-testes e estudo piloto. Cad Saúde Pública 2001; 17:887-96.

25. Berkman LF, Syme SL. Social networks, host resistance, and mortality: a nine-year follow-up study of Alameda County residents. Am J Epidemiol 1979; 109:186-204.
26. Loucks EB, Sullivan LM, D'Agostino RB, Larson MG, Berkman LF, Benjamin EJ. Social networks and inflammatory markers in the Framingham Heart Study. J Biosoc Sci 2006; 38:835-42.

27. Correia CRM. Uso de antidepressivos e benzodiazepínicos em mulheres atendidas em unidades de saúde da família e sua dimensão psicossocial. Rio de Janeiro: Universidade do Estado do Rio de Janeiro; 2013.

28. Berlim MT, Fleck MPA. "Quality of life": a brand new concept for research and practice in psychiatry. Rev Bras Psiquiatr 2003; 25:249-52.

29. Galvão LLLF, Farias MCS, Azevedo PRM, Vilar MJP, Azevedo GD. Prevalência de transtornos mentais comuns e avaliação da qualidade de vida no climatério. Rev Assoc Médica Bras 2007; 53:414-20.

30. Aroca S. Qualidade de vida: comparação entre o impacto de ter transtorno mental comum e a representação do sofrimento dos nervos em mulheres [Dissertação de Mestrado]. Rio de Janeiro: Escola Nacional de Saúde Pública Sergio Arouca, Fundação Oswaldo Cruz; 2009.

31. Evans S, Banerjee S, Leese M, Huxley P. The impact of mental illness on quality of life: a comparison of severe mental illness, common mental disorder and healthy population samples. Qual Life Res 2007; 16:17-29.

32. Cruz LN, Polanczyk CA, Camey SA, Hoffmann JF, Fleck MP. Quality of life in Brazil: normative values for the Whoqol-bref in a southern general population sample. Qual Life Res 2011; 20:1123-9.

33. Artigas NR, Striebel VLW, Hilbig A, de Mello Rieder CR. Evaluation of quality of life and psychological aspects of Parkinson's disease patients who participate in a support group. Dement Neuropsychol 2015; 9:295-300.

34. Ibrahim N, Din NC, Ahmad M, Ghazali SE, Said Z, Shahar S, et al. Relationships between social support and depression, and quality of life of the elderly in a rural community in Malaysia. Asia-Pac Psychiatry 2013; 5:59-66.

35. Onunkwor OF, Al-Dubai SAR, George PP, Arokiasamy J, Yadav H, Barua A, et al. A cross-sectional study on quality of life among the elderly in nongovernmental organizations' elderly homes in Kuala Lumpur. Health Qual Life Outcomes 2016; 14:6.

36. Goncalves DA, Fortes S, Tofoli LF, Campos MR, Mari JJ. Determinants of common mental disorders detection by general practitioners in primary health care in Brazil. Int J Psychiatry Med 2011; 41:3-13.

37. Tófoli LF, Andrade LH, Fortes S. Somatization in Latin America: a review of the classification of somatoform disorders, functional syndromes and medically unexplained symptoms. Rev Bras Psiquiatr 2011; 33 Suppl 1:S59-69.

38. Hawton A, Green C, Dickens AP, Richards SH, Taylor RS, Edwards R, et al. The impact of social isolation on the health status and health-related quality of life of older people. Qual Life Res 2010; 20:57-67.

39. Dickens A, Richards S, Greaves C, Campbell J. Interventions targeting social isolation in older people: a systematic review. BMC Public Health 2011; 11:647. 
40. Baumann C, Erpelding ML, Regat S, Collin JF, Briancon S. The WHOQOL-BREF questionnaire: French adult population norms for the physical health, psychological health and social relationship dimensions. Rev Epidemiol Sante Publique 2010; 58:33-9.

41. Buss PM, Pellegrini Filho A. A saúde e seus determinantes sociais. Physis (Rio J.) 2007; 17:77-93.

42. Departamento de Atenção Básica, Ministério da Saúde. Cadernos de Atenção Básica: saúde mental. Brasília: Ministério da Saúde; 2013.

43. Gonçalves DA, Fortes S, Campos M, Ballester D, Portugal FB, Tófoli LF, et al. Evaluation of a mental health training intervention for multidisciplinary teams in primary care in Brazil: a pre- and posttest study. Gen Hosp Psychiatry 2013; 35:304-8.

\section{Resumo}

O estudo teve como objetivo identificar a associação entre sofrimento emocional e redes de apoio social com qualidade de vida em pacientes de atenção primária. O estudo transversal incluiu 1.466 pacientes nas cidades de São Paulo e Rio de Janeiro, Brasil, entre 2009 e 2010. Foram utilizados o General Health Questionnaire, $a$ Hospital Anxiety and Depression Scale $e$ a versão breve do World Health Organization Quality of Life Instrument. O Índice de Redes Sociais de Apoio classificou os pacientes com as pontuações mais altas e baixas como sendo socialmente integrados ou isolados, respectivamente. Para cada resultado de qualidade vida, foram realizadas uma análise bivariada e quatro regressões lineares múltiplas. As médias para os domínios físico, psicológico, social e ambiental foram, respectivamente: 64,$7 ; 64,2 ; 68,5$ e 49,1. Na análise multivariada, o domínio psicológico mostrou associação negativa com o isolamento, enquanto os domínios social e ambiental foram associados positivamente com a integração. A integração e o isolamento apareceram como fatores importantes para aqueles com sofrimento emocional, já que minimizam ou maximizam os efeitos negativos sobre qualidade de vida.

Atenção Primária à Saúde; Saúde Mental; Qualidade de Vida; Apoio Social
44. Andrade LH, Wang YP, Andreoni S, Silveira CM, Alexandrino-Silva C, Siu ER, et al. Mental disorders in megacities: findings from the Sao Paulo megacity mental health survey, Brazil. PLoS One 2012; $7:$ e31879.

45. Glazer S. Social support across cultures. Int J Intercult Relat 2006; 30:605-22.

\section{Resumen}

El estudio tuvo como objetivo identificar la asociación entre sufrimiento emocional y redes de apoyo social con la calidad de vida en pacientes de atención primaria. El estudio transversal incluyó a 1.466 pacientes en las ciudades de São Paulo y Río de Janeiro, Brasil, entre 2009 y 2010. Se utilizaron el General Health Questionnaire, la Hospital Anxiety and Depression Scale y la versión breve del World Health Organization Quality of Life Instrument. El Índice de Redes Sociales de Apoyo clasificó a los pacientes con las puntuaciones más altas y bajas como estando socialmente integrados o aislados, respectivamente. Para cada resultado de calidad vida, se realizó un análisis bivariado y cuatro regresiones lineales múltiples. Las medias para los dominios físico, psicológico, social y ambiental fueron, respectivamente: 64,7; 64,2; 68,5 y 49,1. En el análisis multivariado, el dominio psicológico mostró una asociación negativa con el aislamiento, mientras los dominios social y ambiental se asociaron positivamente con la integración. La integración y el aislamiento aparecieron como factores importantes para aquellos con sufrimiento emocional, ya que minimizan o maximizan los efectos negativos sobre la calidad de vida.

Atención Primaria de Salud; Salud Mental; Calidad de Vida; Apoyo Social

Submitted on $07 /$ Oct $/ 2015$

Final version resubmitted on 18/Feb/2016

Approved on 11/Mar/2016 